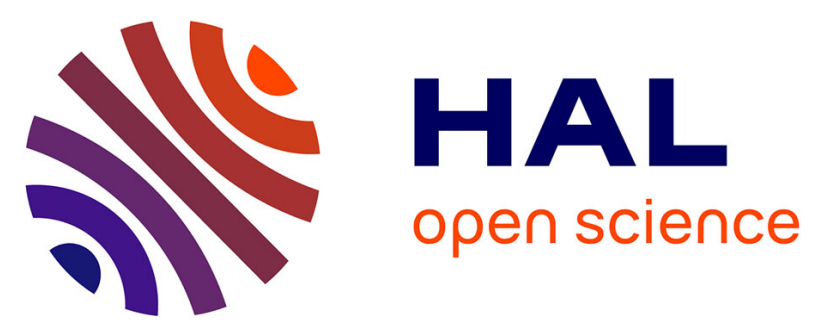

\title{
Modelling bioclogging in variably saturated porous media and the interactions between surface/subsurface flows: Application to Constructed Wetlands
}

R. Samso, J. Garcia, Pascal Molle, N. Forquet

\section{- To cite this version:}

R. Samso, J. Garcia, Pascal Molle, N. Forquet. Modelling bioclogging in variably saturated porous media and the interactions between surface/subsurface flows: Application to Constructed Wetlands. Journal of Environmental Management, 2016, 165, pp.271-279. 10.1016/j.jenvman.2015.09.045 . hal01700725

\section{HAL Id: hal-01700725 \\ https://hal.science/hal-01700725}

Submitted on 5 Feb 2018

HAL is a multi-disciplinary open access archive for the deposit and dissemination of scientific research documents, whether they are published or not. The documents may come from teaching and research institutions in France or abroad, or from public or private research centers.
L'archive ouverte pluridisciplinaire HAL, est destinée au dépôt et à la diffusion de documents scientifiques de niveau recherche, publiés ou non, émanant des établissements d'enseignement et de recherche français ou étrangers, des laboratoires publics ou privés. 


\title{
Modelling bioclogging in variably saturated porous media and the interactions between surface/subsurface flows: application to Constructed Wetlands
}

\author{
Roger Samsóa ab $^{\text {, Joan García }}$, Pascal Molle ${ }^{\mathrm{b}}$, Nicolas Forquet ${ }^{\mathrm{b}, *}$ \\ ${ }^{a}$ GEMMA, Group of Environmental Engineering and Microbiology, Department of \\ Hydraulic, Maritime and Environmental Engineering, Universitat Politècnica de \\ Catalunya-BarcelonaTech, c/Jordi Girona, 1-3, Building D1, E-08034, Barcelona, Spain. \\ ${ }^{b}$ IRSTEA, Freshwater Systems, Ecology and Pollution Research Unit, 5 rue de la Doua, \\ CS70077, 69626 Villeurbanne cedex, France.
}

\begin{abstract}
Horizontal subsurface Flow Constructed Wetlands (HF CWs) are biofilters planted with aquatic macrophytes within which wastewater is treated mostly through contact with bacterial biofilms. The high concentrations of organic carbon and nutrients being transported leads to high bacterial biomass production, which decreases the flow capacity of the porous material (bioclogging). In severe bioclogging scenarios, overland flow may take place, reducing overall treatment performance. In this work we developed a mathematical model using COMSOL Multiphysics ${ }^{T M}$ and MATLAB ${ }^{\circledR}$ to simulate bioclogging effects in HF CWs. Variably saturated subsurface flow and overland flow were described using the Richards equation. The growth of bacteria was described using a Monod equation, and its effects on the hydrodynamics were taken into account by using a conceptual model that adapts the value
\end{abstract}

\footnotetext{
*Corresponding author, phone/fax: +33(0)4 72208787 / +33(0)4 78477875

Email address: nicolas.forquet@irstea.fr (Nicolas Forquet)
} 
of Mualem's unsaturated relative permeability. Simulation results with and without considering bioclogging were compared to showcase the impact of this process on the overall functioning of CWs. The two scenarios rendered visually different bacteria distributions and flow and transport patterns, showing the necessity of including bioclogging effects on CWs models. This work represents one of the few studies available on bioclogging in variably saturated conditions, and the presented model allows simulating the interaction between overland and subsurface flow occurring in most HF CWs. Hence, this work gets us a step closer to being able to describe CWs functioning in an integrated way using mathematical models.

Keywords: surface flow, variably saturated flow, clogging, capillary model, modelling, The Cartridge Theory

\section{List of symbols}

\section{Introduction}

Constructed Wetlands (CWs) are a group of wastewater treatment technologies designed to mimic and intensify pollutants' removal potential of natural wetlands. Like most subsurface environments, the granular material of these systems is prone to clogging (Knowles et al., 2011). This phenomena is responsible for severe changes in the hydrodynamic properties of the granular media i.e. the reduction of both porosity and hydraulic conductivity which result in the proliferation of overland flow (Knowles et al., 2010; Nivala et al., 2012; Pedescoll et al., 2009; Soleimani et al., 2009). Mechanisms responsible for clogging in CWs include biofilm growth, chemical precipitation, filtration and plant roots development (Knowles et al., 2011; Suliman 
et al., 2006). After several years of clogging development, this phenomena can cause the complete failure of CWs. Accordingly, clogging is generally referred to as the main operational problem of CWs (Knowles et al., 2011; Pedescoll et al., 2011).

The experimental study of clogging is complex due to the number of involved parameters, their non-linear cross-influence, the ability to observe non-destructively, and the slow rate of the involved processes (it may take many years for a filter to be completely clogged). Consequently, mathematical models are of great help to study clogging, as they allow observing the outcome of complex systems in various experimental conditions (Oberkampf and Trucano, 2002) and enable a better understanding of the involved processes.

To date, modelling of biological clogging (bioclogging) has been the target of many studies in different disciplines, e.g. soil remediation (Seki et al., 2006), groundwater recharge (Greskowiak et al., 2005) and aquifer thermal energy storage (Bonte et al., 2013). Modelling bioclogging requires coupling flow and transport processes to biofilm growth and the subsequent modification of the hydraulic properties.

Historically, biofilm growth has been modelled using three different approaches based on the scale: microcolony models, biofilm models and macroscopic models (Baveye and Valocchi, 1989). Similarly, the changes of the hydraulic properties can be modelled using pore network models, conceptual models, and empirical laws derived from column experiments (Thullner, 2010). Linking results obtained at these different scales remains challenging because, unlike some abiotic parameters, there do not exist upscaling meth- 
ods for microbial processes (Thullner, 2010). Furthermore, most attempts to simulate bioclogging have been made in saturated conditions, while only a few have focused on variably saturated conditions (Mostafa and van Geel, 2007).

In the field of CWs, only a few attempts have been made to simulate bioclogging (Hua et al., 2013; Knowles et al., 2011; Rousseau et al., 2005) using complex biokinetic models. Brovelli et al. (2009b) compared the performances of three bioclogging models derived from the three different approaches mentioned above to experimental data under saturated conditions and concluded that their models were unable to reproduce long-term clogging evolution. Giraldi et al. (2009, 2010) developed a model (FITOVERT) for vertical flow (VF) CWs including a bioclogging model. The latter uses a semiempirical law (Kozeny-Carman's equation) to modify the saturated hydraulic conductivity according to the biomass concentration but does not modify the unsaturated flow properties. Rajabzadeh et al. (2015) built a model in COMSOL Multiphysics ${ }^{\mathrm{TM}}$ to reproduce the reduction of the hydraulic conductivity caused by bacterial growth observed from a previous experimental study on a vertical-flow wetland mesocosm (Weber and Legge, 2011). They used a simplified biokinetic model, based on Monod's formulation, that considered a single bacteria group and a single substrate. They used the Brinkman equation to describe saturated flow through the porous media and the Kozeny-Carman's equation to translate bacterial growth into porosity reduction.

Despite these attempts, there is still little experience on this field and none of them have been able to predict clogging development in long-term 
scenarios (Nivala et al., 2012). Furthermore, in CWs both saturated and unsaturated sites exist, and when severe clogging occurs, surface flow also develops. Therefore, to simulate bioclogging and its effects on the hydraulic and hydrodynamic functioning of CWs using numerical models, flow under these three conditions must be considered.

In this work we aim to present a standalone model to simulate variably saturated subsurface flow, bioclogging produced by a single bacterial group and the subsequent surface flow. Instead of using empirical models (e.g. Kozeny-Carman's equation) to translate bacteria development into porosity and hydraulic conductivity reduction, we used one of the three conceptual models proposed by Mostafa and van Geel (2007). These three conceptual models are among the very few bioclogging models applicable under variably saturated conditions. The one used in this work (Model no. 3) is of microscopic nature (it calculates the biofilm thickness) and uses a flow reduction factor to affect the macroscopic relative permeability obtained with Mualem's equation (Mualem, 1976), following bacterial growth.

Moreover we present and compare simulation results obtained from two numerical experiments: one accounting for the changes on the hydrodynamic properties of the granular media (by including the conceptual bioclogging model) and the other one neglecting them. Special attention was given to study how the bioclogging model influences the flow regime and the biomass development and distribution.

Later in the paper a discussion is made about the limitations of the current model and on research needs and possible model improvements.

This is the first work to present simulation results with a model able to 
describe bacterial growth, biclogging in variably saturated conditions and the interactions between overland and subsurface flow in horizontal subsurface flow Constructed Wetlands (HF CWs). The presented model brings us a step closer to being able to simulate the overall functioning of CWs, which will occur once it is combined with a complex biokinetic model. With very few modifications, this model can also be applied to related fields of research.

\section{Methods}

\subsection{Governing equations}

\subsubsection{Hydrodynamics}

The Richards equation is used to describe variably saturated porous media flow, assuming that air remains at atmospheric pressure and that the flow velocity can be estimated using the Darcy-Buckingham equation (no creeping flow, Reynolds number < 1) (Eq. 1):

$$
\sigma(h) \frac{\partial h}{\partial t}-\nabla \cdot(K(h) \nabla h)=s_{s}
$$

Where $h[L]$ is the hydraulic head, $t[T]$ is time, $\sigma(h)\left[L^{-1}\right]$ is the specific volumetric storability, $K(h)\left[L T^{-1}\right]$ is the hydraulic conductivity and $s_{s}$ $\left[L T^{-1}\right]$ represents the contribution of sources and sinks.

The constitutive relation between the capillary pressure and the saturation used in this model is that of van Genuchten (1980).

In this work the Richards equation was used to describe both subsurface and overland flow. This choice was primarily driven by the will to keep the same governing equation over the entire flow domain. By doing so, we implicitly assume that there is neither local nor convective acceleration of the 
overland flow and that the viscosity effects can be estimated by a Darcy-like expression. The implications of these assumptions will be discussed later in the manuscript.

\subsubsection{Solute Transport}

The fate and transport of solutes is described using Eq. 2:

$$
{ }_{k=1, \ldots, n} \frac{\partial}{\partial t}\left(\theta C_{k}\right)+\nabla \cdot\left[-\theta D \nabla C_{k}+u C_{k}\right]=s_{C_{k}}+r_{C_{k}}
$$

Where $n$ is the total number of transported species, $C_{k}\left[M L^{-1}\right]$ is the concentration of the $k^{t h}$ solute species, $\theta(-)$ is the liquid volume fraction, $D\left[L^{2} T^{-1}\right]$ is the hydrodynamic dispersion tensor, $u$ is the specific discharge $\left[L T^{-1}\right], s_{C_{k}}\left[M L^{-3} T^{-1}\right]$ represents the source/sink term of $C_{k}$ per unit time and $r_{C_{k}}\left[M L^{-3} T^{-1}\right]$ denotes the reaction rate of $C_{k}$.

\subsubsection{Bacterial Growth}

For the sake of simplicity only one bacterial group $\left(X, m g C O D \cdot L^{-1}\right)$ was considered in the current work. This hypothetical bacteria grows using the organic substrate $C\left(m g C O D \cdot L^{-1}\right)$ and its growth rate is described using the following Monod equation (Eq. 3).

$$
\frac{\partial X}{\partial t}=\mu_{X}\left(1-\frac{X}{\rho_{X}\left(\theta_{s}-\theta_{r}\right)}\right)\left(\frac{C}{K_{X, C}+C}\right) X-k_{X} X
$$

Where $\mu_{X}$ and $k_{X}$ (both in $d^{-1}$ ) are the maximum specific growth rate and decay rate of $X$, respectively, and $K_{X, C}\left(m g \cdot L^{-1}\right)$ represents the half saturation coefficient of $C$ for $X$. 
The logistic term $\left(1-\frac{X}{\rho_{X}\left(\theta_{s}-\theta_{r}\right)}\right)$ was added to Eq. 3 to prevent unlimited growth of $X$ in areas with persistently high $C$ concentrations (inlet section) (Samsó and García, 2013a,b). In this function, $\rho_{X}\left(\mathrm{~kg} \cdot \mathrm{m}^{-3}\right)$ represents the density of $X$ and $\theta_{s}(-)$ and $\theta_{r}(-)$ represent the saturated and residual liquid volume fractions of the porous material, respectively. Note that this hypothetical bacterial group grows without neither electron acceptors nor nutrients limitations.

Substrate $C$ degradation rate is obtained with the following expression:

$$
\frac{\partial C}{\partial t}=-\frac{1}{Y_{X, C}} \mu_{X}\left(1-\frac{X}{\rho_{X}\left(\theta_{s}-\theta_{r}\right)}\right)\left(\frac{C}{K_{X, C}+C}\right) X
$$

Where $Y_{X, C}\left(m g C O D_{X} \cdot m g C O D_{C}{ }^{-1}\right)$ is the yield coefficient for bacteria $X$ on substrate $C$. Eq. 4 corresponds to the reaction term $r_{C}$ in Eq. 2 .

\subsubsection{Bioclogging}

Bioclogging is described using model 3 of Mostafa and van Geel (2007). The relation between capillary pressure $\left(P_{c}\right.$, in $\left.P a\right)$ and specific saturation ( $S_{e}$, unitless) of the porous media is obtained using Eq. 5 (van Genuchten, $1980)$.

$$
P_{c}=\frac{\left(S_{e}^{-\frac{1}{m}}-1\right)^{\frac{1}{n}}}{\alpha}
$$

In Eq. 5, parameters $\alpha\left(m^{-1}\right), n(-)$ and $m(-)$ are van Genuchten parameters.

The saturation range is then discretized in $i=1 \ldots n$ equal divisions, and the capillary head corresponding to the mid point of each of these divisions 
is used to calculate the radius of the equivalent capillary tube. For division $i$, using the capillary model, $r_{i}$ equals (Eq. 6):

$$
r_{i}=-\frac{2 \sigma \cos \beta}{P_{c_{i}}}
$$

Where $\sigma$ is the water surface tension $\left(0.072 N \cdot m^{-1}\right.$ for distilled water at $20^{\circ} \mathrm{C}$ ) and $\beta(-)$ is the water contact angle within the tube walls, which is usually set to 0 (Rosenzweig et al., 2009).

For the $i^{t h}$ division, the number of pores $\left(N_{i}\right)$ is obtained by dividing its void volume by the cross sectional area of the corresponding capillary tube (Eq. 7).

$$
N_{i}=\frac{\Delta \theta}{\pi r_{i}^{2}}
$$

Where $\Delta \theta(-)$ are increments of the water content between two consecutive pore radii.

Using the microbial volume $\left(V_{m}=\rho_{X} \cdot X\right.$, expressed as an area per unit cross-sectional area) obtained from the biokinetic model, the biofilm thickness $(t h$, in $m)$ is obtained at every time step by solving the following equation:

$$
V_{m}=\sum_{i=1}^{n}\left[N_{i} \pi r_{i}^{2}-N_{i} \pi\left(r_{i}-t h\right)^{2}\right]
$$

Then, the unsaturated permeability of Mualem (1976) is adapted by multiplying it by the flow factor $U$ (Eq. 9), which corresponds to the ratio between the flow-rate affected by biofilm (of thickness th) and that under biofilm-free conditions. Both flow-rates are calculated using the HagenPoiseuille equation for laminar flow in a pipe. 


$$
U=\frac{\sum_{i=1}^{n} N_{i} \pi\left(r_{i}-t h\right)^{4}}{\sum_{i=1}^{n} N_{i} \pi r_{i}^{4}}
$$

Then, the unsaturated biofilm-affected relative hydraulic conductivity is obtained with Eq. 10:

$$
k_{r}\left(S_{e}\right)=S_{e}^{\frac{1}{2}}\left[1-\left(1-S_{e}^{\frac{1}{m}}\right)^{m}\right]^{2} U
$$

It is important to note that the presented model does not rely solely on the Hagen-Poiseuille equation for hydraulic conductivity calculation but also relies on Mualem's equation, which includes a term describing tortuosity.

The updated water content and the specific saturation in the presence of biofilm are obtained with Eq. 11 and 12 respectively (Rosenzweig et al., 2009):

$$
\begin{gathered}
\theta=\theta_{r}+\pi \sum_{i=1}^{n} N_{i}\left(r_{i}-t h\right)^{2} \\
S_{e}=\frac{\theta-\theta_{r}}{\theta_{s}-\theta_{r}}
\end{gathered}
$$

The value of $\theta$ ranges from $\theta_{r}$ to $\theta_{s}-V_{m}$. For those pores that are full of bacteria (radius smaller than or equal to the biofilm thicknes), the water content inside $(\theta)$ is equal to $\theta_{r}$.

Finally, the hydraulic conductivity of the granular media is obtained with:

$$
K\left(S_{e}\right)=k_{r}\left(S_{e}\right) K_{\text {sat }}
$$

Where $K_{\text {sat }}\left(m \cdot d^{-1}\right)$ is the hydraulic conductivity of the granular media under fully saturated conditions. 
For further details on this conceptual model the reader is referred to the original source (Mostafa and van Geel, 2007).

\subsection{Discretization of the saturation range}

The effect of the discretization of the saturation range on simulation results was studied by comparing the total pore area and the thickness of biofilm (for $V_{m}=0.3$ ) obtained with discratizations of 10, 100, 1000, 10000 and 100000 divisions.

\subsection{Model Implementation}

Figure 1 shows the steps taken during the numerical solution of the model equations presented in previous sections. All equations were implemented using the COMSOL Multiphysics ${ }^{\mathrm{TM}} \mathrm{v} 4.3 \mathrm{~b}$ interface, except for the equations used to calculate the relative hydraulic conductivity in the presence of biofilm $\left(k_{r}\right)$ and the volumetric water content $(\theta)$ (Eqs. 10 and 11), that were implemented in MATLAB ${ }^{\circledR}$. The exchange of data between COMSOL Multiphysics ${ }^{\mathrm{TM}}$ and MATLAB ${ }^{\circledR}$ is made at each numerical iteration using the Livelink for MATLAB ${ }^{\circledR}$ COMSOL Multiphysics ${ }^{\mathrm{TM}}$ module.

\subsection{Geometrical description}

A longitudinal section of a generic CW is represented by three $2 \mathrm{D}$ subdomains: two belowground subdomains, representing the mixing zone $(M Z)$ and the body of the wetland $(W B)$, respectively, and a runoff $(R L)$ layer on top of the previous two (Figure 2). Note that in this work the term runoff was used following the nomenclature used by Weill et al. (2009) and is used indistinctly to describe surface/overland flow. 


\subsection{Meshing}

A triangular mesh was built automatically with COMSOL Multiphysics ${ }^{\mathrm{TM}}$ us- $^{-}$ ing the advancing front algorithm and by setting the specific parameter values for each subdomain. The resulting mesh, consisting of a total of 15358 elements, has higher elements density in the $R L$ and lower density in the belowground subdomains $(M Z$ and $W B$ ). Note that a predefined number of 350 triangular elements was set in boundary $B 4$ so that the mass of water would be preserved from inlet to outlet. In Table 1 all mesh parameters are described in detail.

\subsection{Model features and Input parameters}

The values assigned to the biokinetic parameters of Eqs. 3 and 4 are shown in Table 2.

Bacterial growth is assumed to take place only in the belowground subdomains $(M Z$ and $W B$ ), and the changes in the hydrodynamics of the granular media caused by bacterial growth only apply to the $W B$ subdomain. That is because the granular media of the $M Z$ is generally coarser than that of the $W B$, and thus the impact of bacterial growth on the hydrodynamic properties of the former is much smaller than that on the latter. The water retention curves of all subdomains are calculated using the van Genuchten parameters shown in Table 3 and remain constant over time. Only in the $W B$ the relative permeability and the water content are updated over time (Eqs. 10 and 11). 


\subsection{Numerical experiment}

To showcase the importance of including bioclogging in CWs models, 2 simulations were run, one considering bioclogging effects on the hydrodynamics of the granular media and another one neglecting them. The two simulations were run to describe 125 days of bioclogging development. The time stepping method used in both cases was the BDF (backward differentiation formula) of variable order of accuracy (one to five). With this method, a high order is used when possible, and a lower order is automatically employed when improved stability is required.

A visual comparison of the bacteria and substrate distribution and the hydraulic conductivity obtained with the two simulations is made by plotting them within the $2 \mathrm{D}$ domain. This qualitative comparison is complemented with a quantitative comparison of three different outputs of the two simulations: (i) the center of mass of bacteria, (ii) the percentage of pore volume occupied within the $W B$ and (iii) the proportion of flow circulating in the $R L$ and through the $W B$.

The coordinates of the center of mass of bacteria $\left(x_{C M}, y_{C M}\right)$ in the $W B$ over time are obtained with Eqs. 14 and 15 (French et al., 2001):

$$
\begin{aligned}
x_{C M}(t) & =\frac{\iint X(t) x d x d y}{\iint X(t) d x d y} \\
y_{C M}(t) & =\frac{\iint X(t) y d x d y}{\iint X(t) d x d y}
\end{aligned}
$$

Where $x$ and $y$ are the Cartesian coordinates of the subsurface subdomains $(M Z$ and $W B)$. 
The percentage of pore space occupied by bacteria is obtained with Eq. 16:

$\%$ occupied $=\frac{\text { Pore Volume occupied }}{\text { Total Pore Volume }} \cdot 100=\frac{\frac{\iint X d x d y \cdot W_{W B}}{\rho_{X}}}{\left(\theta_{s}-\theta_{r}\right) \cdot L_{W B} \cdot W_{W B} \cdot D_{W B}} \cdot 100$

Where $L_{W B}, W_{W B}$ and $D_{W B}($ all in $m$ ) are the length, width and depth of the wetland body subdomain, respectively.

Finally, the proportion of flow passing through the $R L$ is obtained by integrating the vertical component of the flow velocity vector $\left(v_{y}\right)$ over boundary $B 6$, while the flow passing through the $W B$ is calculated by integrating the horizontal component of the flow velocity vector $\left(v_{x}\right)$ over boundary $B 8$.

\subsection{Boundary and Initial Conditions}

For the Richards equation (Eq. 1), a flow-rate of $1.4 m \cdot d^{-1}$ (Neumann) was imposed in boundary $B 1$ and a hydraulic head of $0.5 \mathrm{~m}$ (Dirichlet) at boundary $B 4$. We set the initial pressure heads to be at hydrostatic equilibrium. For any node of elevation $y$, the initial pressure head equals $(0.5-y) m$, and the origin of coordinates is located at the bottom left corner of the domain.

For the transport equation (Eq. 2) a flux of $400 \mathrm{mgC} \cdot \mathrm{L}^{-1}$ was imposed at boundary $B 1$ (Cauchy) and an outflow boundary condition was applied at boundary $B 4$, which assumes convection is the dominating transport mechanism, thus neglecting diffusive transport. The initial concentration of $C$ was set to $0 \mathrm{mg} \cdot \mathrm{L}^{-1}$ for all three subdomains.

The rest of boundaries were defined as no-flow boundaries. Also note that 
both the flow-rate and the flux of $C$ imposed at boundary $B 1$ were limited to nodes below $y=0.5 \mathrm{~m}$ to avoid unwanted diffusion of $C$ in the $R L$.

The initial concentrations of bacteria $X$ were set to $1 \mathrm{mg} \cdot \mathrm{L}^{-1}$ in the belowground subdomains to recreate pristine conditions, and $0 \mathrm{mg} \cdot \mathrm{L}^{-1}$ on the $R L$.

\section{Results}

Table 4 shows that the area of pores obtained with the different discretizations of the saturation range (with 10, 100, 1000, 10000 and 100000 divisions) differs only at the $13^{\text {th }}$ decimal place, while the biofilm thickness obtained with the smallest and coarsest discretizations differ in less than $1 \%$.

Notably different bacteria distributions and flow and transport patterns were obtained from the two numerical experiments (Figures 3, 4 and 5).

When omitting bioclogging effects, bacterial biomass occupies the entire depth of the system and progresses from inlet to outlet over time (while there is substrate left to degrade) (Figure 3, left). This is due to the fact that in this numerical experiment the hydraulic conductivity does not change over time and all water flow and pollutant transport take place through the subsurface domains (no overland flow) regardless of the biomass concentration (Figures 4 and 5 , left).

On the other hand, when bioclogging is simulated, the progressive decrease of the hydraulic conductivity over time caused by bacterial growth modifies the flow and transport patterns, which in turn affect bacteria distribution (Figures 3, 4 and 5, right). During the initial days (before day 10), bacteria grows showing similar trends as when neglecting bioclogging. 
From then, the hydraulic conductivity in the $W B$ is sufficiently low so that around $80 \%$ of the inflow water is forced to circulate overland (Figure 6). When the overland flow finds sufficiently high hydraulic conductivities underneath, it reinfiltrates in the granular media. This phenomenon causes the elongated shape of bacteria near the surface of the bed, which is corroborated by the evolution of the location of the center of mass of bacteria within the wetland (Figure 7 ). While the $x$ coordinate of the center of mass remains relatively similar for the two simulations (with and without bioclogging), the $y$ coordinate evolves quite differently over time. Indeed, when considering bioclogging effects the $y$ coordinate initially displaces towards the surface of the bed and stabilizes thereafter, while in the absence of bioclogging it remains fairly stable at all times. Note as well, that the decrease of the value of the $x$ coordinate during the initial days of the two simulations is due to the fact that the same initial concentration of $X$ was set for the two subsurface domains $(M Z$ and $W B)$. Since substrate $C$ enters through the left boundary of the domain, the highest bacteria development takes place initially in that region, displacing the $x$ coordinate of the center of mass towards there. When the bacteria concentration near the inlet reaches the carrying capacity of the system $\left(\left(\theta_{s}-\theta_{r}\right) \cdot \rho_{X}=0.38 \mathrm{~kg} \cdot \mathrm{m}^{-3}=380 \mathrm{mg} \cdot \mathrm{L}^{-1}\right)$, and since there is still sufficient concentration of $C$ to allow bacterial growth, the $x$ coordinate displaces progressively towards the outlet (higher $x_{C G}$ values). Despite the different bacteria distributions, Figure 8 shows that the percentage of the bed porosity occupied by bacteria in the two simulations was identical. 


\section{Discussion}

\subsection{Model equations}

The mathematical modelling of the hydraulics of HF CWs requires equations to describe variably saturated subsurface flow and overland flow. In hydrology, the interaction between surface and subsurface flows is usually simulated by coupling any form of the Richards equation for the subsurface variably saturated flow with the Saint-Venant equations (or any of its approximations i.e. the shallow water equations) for the surface flow (Furman, 2008). The coupling between the two has been subject of intensive research since the late 1960's and several models have been developed for that purpose (Panday and Huyakorn, 2004; Kollet and Maxwell, 2006).

Weill et al. (2009) indicates that with the inertia approximation of SaintVenant equations, runoff can be simulated as a flow in a porous medium, since the flow-rate is proportional to the hydraulic gradient. Their model includes a one-element thick layer on top of the porous media with modified hydraulic parameters in order to match those of a simplified surface flow equation. In this work we failed to reproduce their results using COMSOL Multiphysics ${ }^{\mathrm{TM}}$, since the stability of their model depended greatly on the numerical method utilized (mixed-hybrid finite elements). However, using similar assumptions we used the Richards equation to simulate both subsurface flow and overland flow. These assumptions are in essence those used for the shallow water equations: low flow-rates and shallow water depths. Unlike Weill et al. (2009), the van Genuchten parameters of the Richards equation for the $R L$ were selected with the sole purpose of assimilating flow in porous media to overland flow, hence they lack any physical meaning. The same occurs for its 
saturated hydraulic conductivity, which was set to very high values to reduce flow resistance, and for $\theta_{r}$ and $\theta_{s}$, which were defined as 0 and 1 , respectively, so that all pore volume would be considered as water only. In contrast, although in VF CWs ponding also occurs, the surface water remains mostly in hydrostatic conditions and thus a changing hydraulic head boundary condition is sufficient to simulate this phenomena (Forquet et al., 2009; Giraldi et al., 2010) as long as the inflow is evenly distributed.

In this work we used one of the three conceptual models by Mostafa and van Geel (2007) to translate biomass growth into relative permeability reduction. This model was selected over the Kozeny-Carman equation, which is a semi-empirical relation between the permeability and the porosity of the granular material. Due to its empirical and macroscopic nature, the Kozeny-Carman equation does not consider neither the biofilm structure nor the pore size distribution and cannot be directly verified nor it can provide any insights on the bioclogging process. On the contrary, the conceptual bioclogging model by Mostafa and van Geel (2007) was originally conceived for variably saturated conditions and its main advantage is that it takes into account the pore size distribution of the granular media.

Mostafa and van Geel (2007) discretized the saturation range in 20 divisions. In the present work the effect of the discretization range on the water retention curve, the total pore volume and the biofilm thickness was studied, and very similar results were obtained regardless of the size of divisions. However, a higher number of divisions of the saturation range was seen to facilitate numerical convergence, and for this reason a discretization of 500 was selected. 


\subsection{Assumptions and limitations}

In CWs clogging phenomena is attributed to several factors including plant roots development, solids accumulation and bacterial growth (Knowles et al., 2011). In this work we followed a deliberate approach to simplify the real complexity of CWs and clogging was exclusively attributed to the growth of a single bacterial group which degrades a single substrate $(X$ and $C$, respectively). Moreover inert solids coming from bacteria decay and from wastewater, which are known to accumulate in the granular media over time, were not considered in the model and do not cause any clogging effects (Samsó and García, 2014a; Weintraub et al., 2002).

Temperature effects on bacteria growth were not included either, and according to Samsó and García (2013a) the inclusion of temperature in the bacterial growth expressions was required to match effluent pollutant concentrations of a pilot $\mathrm{HF}$ CW in the long-term.

In this work we also assumed that neither bacterial growth nor substrates degradation take place in the $R L$. In CWs operated under average conditions, although bioclogging might occur in several regions, overland flow infiltrates rapidly once the clogged area is surpassed and the changes in bacteria concentrations during their transport in contact with the atmosphere are negligible in comparison to those occurring in the interstitial pore space.

Moreover, as a result of the assumptions required to use the Richards equation for overland flow, mentioned in previous sections, the presented model can only be used for low flow-rates and surface water depths. Moreover, the inlet section (boundary $B 1$ ) had to be set only in the nodes below $y=0.5$ because the $R L$ domain was defined as a fully saturated porous me- 
dia $\left(S_{e}=1\right)$ and thus diffusion in that subdomain may take place even when there is no advective flow of water on it.

Finally, the theory of capillary flow states that the smaller pores of a porous media are responsible for flow for high capillary pressures (low saturation), while when the capillary pressure decreases (growing saturation) the pores of bigger size progressively start to contribute to the flow as well. For this reason, it is generally accepted that the pores of smaller radius should clogg first, since even under low saturation conditions they are full of water. However, the model by Mostafa and van Geel (2007) is formulated on the assumption that all pores have the same biofilm thickness regardless of their size (Figure9). This means that even if the pores of larger radius are not filled with water, biofilm still grows in them. To this regard Mostafa and van Geel (2007) argue that this approach might be justified by the fact that all pores have a residual water content on them that allows the development of bacteria, even when they are empty of water.

\subsection{Model results}

Results of the numerical experiment clearly demonstrate the importance of considering bioclogging effects and the resulting overland flow for a sound description of the general functioning of HF CWs using numerical models.

Although not shown in this document, results of preliminary simulations indicate that the higher the inflow concentration of $C$ and the flow-rate, the wider the longitudinal bacteria distribution. On the contrary, lower values of $\left(\theta_{s}-\theta_{r}\right)$ translate into a narrower bacterial distribution. Moreover, the widespread of bacteria when considering bioclogging also depends on the relative proportion of overland and subsurface flows. In contrast, most of the 
other parameters considered in this model only affect the velocity at which clogging developed.

The rapid bacterial growth and porosity occupation observed in this work were on the one hand due to the lack of limiting substrates and inhibitors, and on the other hand to the fact that all model parameters were chosen so that the simulation time required to obtain relevant results would be shortened. This same strategy was used in the work of Soleimani et al. (2009) to reduce computation time. Thus, high values of inflow $C$ concentration, yield coefficient $\left(Y_{X, C}\right)$ and maximum specific growth rate $\left(\mu_{X}\right)$ and low values for decay rate $\left(k_{X}\right)$, saturation coefficient $\left(K_{X, C}\right)$ and initial saturated hydraulic conductivity $\left(K_{\text {sat }}\right)$ were selected. On the other hand, a low value for the inflow rate was used $\left(1.4 \mathrm{~m} \cdot \mathrm{d}^{-1}\right)$ so that the hypothesis of slow flow velocities and shallow water depth for the overland flow are fulfilled.

It is also interesting to note that, in addition to surface flow, a preferential flow-path also develops at the bottom of the granular media, where bacterial concentrations are smaller (Figure 4, right). In CWs this phenomena has already been reported and attributed to the combined effect of the higher biomass concentrations (due to their higher yields of aerobic bacteria groups as compared to anaerobic ones) and higher belowground plant biomass near the surface of the bed (Parr, 1990; Reed et al., 1995; Rousseau et al., 2005; Samsó and García, 2013a; Samsó and García, 2014a).

Although the difference between the bacterial distribution and the flow pattern obtained from the two simulations increased over time, the percentage of porosity occupied was the same for the two cases. Based on this result alone, it could be argued that bioclogging does not have an effect CWs' 
lifespan. However, the distribution of bacteria within the wetland is also important on their overall functioning. Indeed, everything seems to indicate that following the trend observed in Figure 3, if bacteria growing near the surface were to reach to outlet section of the wetland, water would pond on the surface and the wetland would either flood or start working with vertical flow. This phenomena, although influenced by other factors such as surface sludge accumulation, has already been documented in HF CWs (Knowles et al., 2010).

Despite the differences in the numerical experiment set-up and the type of biofilter simulated, bacteria dynamics obtained in this work and those obtained by Soleimani et al. (2009) followed similar trends. Soleimani et al. (2009) simulated bioclogging using model 1 of Mostafa and van Geel (2007) on a two-dimensional vertical-flow septic bed, represented as a $1 \mathrm{~m}$-side square. Their septic bed was fed vertically on the top left corner of their domain $\left(0.046 \mathrm{~cm} \cdot d^{-1}\right.$ and $\left.2000 \mathrm{mg} \cdot \mathrm{L}^{-1}\right)$. In the current work the domain was a $5.3 m$ by $0.6 m \mathrm{HF}$ CW (Figure 2), fed horizontally on the left boundary $\left(1.4 m \cdot d^{-1}\right.$ and $\left.400 m g \cdot L^{-1}\right)$. Soleimani et al. (2009) neglected bioclogging effects on the first row of elements on top of the domain, which allowed the horizontal movement of water when the conductance of the media underneath was too low. In the current study, bioclogging was neglected on the $M Z$ to avoid numerical issues caused by increasing pore velocities following porosity reduction. In both studies, if detachment/sloughing processes had been considered, the biofilm thickness in regions of high flow rates (high shear stress) would auto-regulate (Kapellos et al., 2007), and these assumption would no longer be required. 
In Soleimani et al. (2009) the areas that clogged the fastest were those close to the inlet section, and then water moved horizontally until it found sufficiently high hydraulic conductivities underneath. In fact, the authors state that after 56 days of simulation the $1 \mathrm{~m}$ section of their septic bed was effectively clogged. Similarly, Knowles et al. (2011) found that in most HF CWs, the hydraulic conductivity near the inlet section was at least one order of magnitude smaller than near the outlet, and consequently surface flow most often takes place in the inlet section. In our study, the initial hydraulic conductivity of the $W B$ was $100 m \cdot d^{-1}$, and after bacteria developed the hydraulic conductivity decreased to around $10 \mathrm{~m} \cdot \mathrm{d}^{-1}$.

Previous research with biokinetic models for CWs has shown the importance of the concentration of dissolved oxygen in the dynamics of the bacterial communities within these systems (Samsó and García, 2013b). When bioclogging develops the transport of oxygen is hindered and a similar effect occurs when water ponds on the surface of these systems for long periods of time. Therefore, it is likely that different bacterial distributions and flow and transport patterns would have been obtained if dissolved oxygen had been included in the current model.

Samsó and García (2014a) proposed The Cartridge Theory to describe the general functioning of CWs. This theory was exclusively developed for HF CWs (does not apply for VF CWs) and assimilates the granular media of these systems to a generic cartridge, which is consumed (clogged) with inert solids from inlet to outlet over time. In this work clogging caused by inert solids accumulation was not considered and therefore the bacterial distribution obtained in the present work cannot be directly compared to the 
results of Samsó and García (2013a). Moreover Samsó and García (2014a) used a very complex biokinetic model, which considered, among other things, dissolved oxygen and the competition between different bacterial groups for certain substrates.

\subsection{Further research needs and model improvements}

Although the objective of the current work was not to obtain accurate predictions of bioclogging development in CWs, validation of the model should be provided. Moreover, a sensitivity analysis would help to identify the sensitivity of the model output to prescribed perturbations on the values of the input parameters. Among the parameters used in the current model, those affecting bacterial growth rates (Table 2) as well as the saturated hydraulic conductivity of the $W B\left(K_{\text {sat }}\right)$ would be of great interest.

In the current work we studied the effect of bioclogging development on the hydrodynamics and bacteria distribution in CWs. However, the other major clogging contributor i.e. solids entrapment and accumulation was not taken into account. Previous studies have shown the impact accumulated solids may have on general wetlands functioning (Samsó and García, 2014a). Therefore the next logical step in the development of the presented model would be the inclusion of solids accumulation. This hypothetical work would allow to determine how these solids affect bacterial growth and if bioclogging accelerates the rate at which solids accumulate.

Likewise, future works could also be dedicated to improve the mathematical description of overland flow and transport.

Additionally, the bioclogging model presented in work could be combined with existing biokinetic models for CWs, such as the BIO_PORE model 
(Samsó and García, 2013a), to obtain more realistic results. The BIO_PORE was also built in COMSOL Multiphysics ${ }^{\mathrm{TM}}$, and would therefore facilitate the coupling between the two.

\section{Conclusions}

In this paper we presented a standalone model built on COMSOL Multiphysics ${ }^{\mathrm{TM}}$ to simulate bioclogging and surface/subsurface flow interactions in horizontal subsurface flow Constructed Wetlands (CWs). A numerical experiment was also carried out to showcase the importance of including bioclogging to obtain a sound description of the functioning of these systems. The numerical experiment consisted in comparing several model outputs for two different simulations: one considering bioclogging effects on the hydrodynamics of the granular media and the other one neglecting them.

Different bacteria distributions and flow patterns were obtained from the two simulations. When considering bioclogging, overland flow started to take place before 10 days of simulated time. The existence of overland flow also resulted in an elongated shape of bacteria near the surface of the bed. This elongated shape was also responsible of the observed drift of the center of mass of bacteria towards the top of the central section of the subsurface subdomains. On the other hand, the percentage of porosity occupied by bacteria obtained for the two simulations was almost identical. This fact was attributed to the short simulated time considered in this chapter.

In order to approximate the simulated results to the real functioning of wetlands, the formulation presented in this work should be combined with more robust models for CWs already available such as the BIO_PORE model 
(Samsó and García, 2013a).

Further research on this model should include a parametric sensitivity analysis in order to establish the relative impact of each model parameter on the different model outputs.

\section{Acknowledgements}

Authors are grateful to the European Comission for the financial support of the SWINGS Project (Grant Agreement N: 308502). Roger Samsó also acknowledges the scholarship provided by the Universitat Politècnica de Catalunya (UPC).

\section{References}

Baveye, P., Valocchi, A., 1989. An Evaluation of Mathematical Models of the Transport of Biologically Reacting Solutes in Saturated Soils and Aquifers. Water Resources Research 25, 1413-1421.

Bonte, M., Van Breukelen, B.M., Stuyfzand, P.J., 2013. Environmental impacts of aquifer thermal energy storage investigated by field and laboratory experiments. Journal of Water and Climate Change 4, 77-89.

Brovelli, A., Malaguerra, F., Barry, D., 2009b. Bioclogging in porous media: Model development and sensitivity to initial conditions. Environmental Modelling \& Software 24, 611-626.

Forquet, N., Wanko, A., Molle, P., Mosé, R., Sadowski, A.G., 2009. Twophase flow modelling for oxygen renewal estimation in vertical flow filter: luxury or necessity? Water Science \& Technology 59, 2311-9. 
French, H.K., Van der Zee, S.E., Leijnse, A., 2001. Transport and degradation of propyleneglycol and potassium acetate in the unsaturated zone. Journal of Contaminant Hydrology 49, 23-48.

Furman, A., 2008. Modeling Coupled SurfaceSubsurface Flow Processes: A Review. Vadose Zone Journal 7, 741-756.

van Genuchten, M.T., 1980. A closed-form equation for predicting the hydraulic conductivity of unsaturated soils.

Giraldi, D., de Michieli Vitturi, M., Iannelli, R., 2010. FITOVERT: A dynamic numerical model of subsurface vertical flow constructed wetlands. Environmental Modelling \& Software 25, 633-640.

Giraldi, D., de Michieli Vitturi, M., Zaramella, M., Marion, A., Iannelli, R., 2009. Hydrodynamics of vertical subsurface flow constructed wetlands: Tracer tests with rhodamine WT and numerical modelling. Ecological Engineering 35, 265-273.

Greskowiak, J., Prommer, H., Massmann, G., Johnston, C.D., Nützmann, G., Pekdeger, A., 2005. The impact of variably saturated conditions on hydrogeochemical changes during artificial recharge of groundwater. Applied Geochemistry 20, 1409-1426.

Hua, G.F., Li, L., Zhao, Y.Q., Zhu, W., Shen, J.Q., 2013. An integrated model of substrate clogging in vertical flow constructed wetlands. Journal of environmental management 119, 67-75.

Kapellos, G.E., Alexiou, T.S., Payatakes, A.C., 2007. Hierarchical simulator 
of biofilm growth and dynamics in granular porous materials. Advances in Water Resources 30, 1648-1667.

Knowles, P., Dotro, G., Nivala, J., García, J., 2011. Clogging in subsurfaceflow treatment wetlands: Occurrence and contributing factors. Ecological Engineering 37, 99-112.

Knowles, P.R., Griffin, P., Davies, P.a., 2010. Complementary methods to investigate the development of clogging within a horizontal sub-surface flow tertiary treatment wetland. Water research 44, 320-30.

Kollet, S.J., Maxwell, R.M., 2006. Integrated surfacegroundwater flow modeling: A free-surface overland flow boundary condition in a parallel groundwater flow model. Advances in Water Resources 29, 945-958.

Mostafa, M., van Geel, P.J., 2007. Conceptual Models and Simulations for Biological Clogging in Unsaturated Soils. Vadose Zone Journal 6, 175.

Mualem, Y., 1976. A new model for predicting the hydraulic conductivity of unsaturated porous media. Water Resources Research 12, 513-522.

Nivala, J., Knowles, P., Dotro, G., García, J., Wallace, S., 2012. Clogging in subsurface-flow treatment wetlands: measurement, modeling and management. Water research 46, 1625-40.

Oberkampf, W.L., Trucano, T.G., 2002. Verification and validation in computational fluid dynamics. Progress in Aerospace Sciences 38, 209-272.

Panday, S., Huyakorn, P.S., 2004. A fully coupled physically-based spatially- 
distributed model for evaluating surface/subsurface flow. Advances in Water Resources 27, 361-382.

Parr, T., 1990. Factors affecting reed (Phragmites australis) growth in UK reed bed treatment systems, in: Constructed Wetlands in Water Pollution Control. Pergamon Press, Oxford, UK, pp. 67-76.

Pedescoll, A., Corzo, A., Alvarez, E., García, J., Puigagut, J., 2011. The effect of primary treatment and flow regime on clogging development in horizontal subsurface flow constructed wetlands: An experimental evaluation. Water research 45, 3579-89.

Pedescoll, A., Uggetti, E., Llorens, E., Granés, F., García, D., García, J., 2009. Practical method based on saturated hydraulic conductivity used to assess clogging in subsurface flow constructed wetlands. Ecological Engineering 35, 1216-1224.

Rajabzadeh, A.R., Legge, R.L., Weber, K.P., 2015. Multiphysics modelling of flow dynamics, biofilm development and wastewater treatment in a subsurface vertical flow constructed wetland mesocosm. Ecological Engineering 74, 107-116. URL: http://linkinghub.elsevier.com/retrieve/pii/S0925857414005369, doi:10.1016/j.ecoleng.2014.09.122.

Reed, S.C., Crites, R.W., Middlebrooks, E.J., 1995. Natural Systems for Waste Management and Treatment. McGraw-Hill Professional Publishing.

Rosenzweig, R., Shavit, U., Furman, A., 2009. The Influence of Biofilm 
Spatial Distribution Scenarios on Hydraulic Conductivity of Unsaturated Soils. Vadose Zone Journal 8, 1080-4.

Rousseau, D., Griffin, P., Vanrolleghem, P., De Pauw, N., 2005. Model Study of Short-Term Dynamics of Secondary Treatment Reed Beds at Saxby (Leicestershire, UK). Journal of Environmental Science and Health, Part A $40,1479-1492$.

Samsó, R., García, J., 2013a. BIO_PORE, a mathematical model to simulate biofilm growth and water quality improvement in porous media: Application and calibration for constructed wetlands. Ecological Engineering 54, $116-127$.

Samsó, R., García, J., 2013b. Bacteria distribution and dynamics in constructed wetlands based on modelling results. Science of The Total Environment 461-462, 430-440.

Samsó, R., García, J., 2014a. The Cartridge Theory: A description of the functioning of horizontal subsurface flow constructed wetlands for wastewater treatment, based on modelling results. Science of The Total Environment 473-474, 651-658.

Seki, K., Thullner, M., Hanada, J., Miyazaki, T., 2006. Moderate Bioclogging Leading to Preferential Flow Paths in Biobarriers. Ground Water Monitoring \& Remediation 26, 68-76.

Soleimani, S., Van Geel, P.J., Isgor, O.B., Mostafa, M.B., 2009. Modeling of biological clogging in unsaturated porous media. Journal of contaminant hydrology 106, 39-50. 
Suliman, F., French, H., Haugen, L., Sovik, A., 2006. Change in flow and transport patterns in horizontal subsurface flow constructed wetlands as a result of biological growth. Ecological Engineering 27, 124-133.

Thullner, M., 2010. Comparison of bioclogging effects in saturated porous media within one- and two-dimensional flow systems. Ecological Engineering , 176-196.

Weber, K.P., Legge, R.L., 2011. Dynamics in the bacterial community-level physiological profiles and hydrological characteristics of constructed wetland mesocosms during start-up. Ecological Engineering 37, 666-677.

Weill, S., Mouche, E., Patin, J., 2009. A generalized Richards equation for surface/subsurface flow modelling. Journal of Hydrology 366, 9-20.

Weintraub, L., Chen, C.W., Tsai, W., Herr, J., Goldstein, R.A., Siegrist, R., 2002. Modifications of WARMF to asses the efficacy of onsite wastewater systems on public health, in: Proceedings of the Water Environment Federation, Water Environment Federation. pp. 152-165(14). 


\begin{tabular}{|c|c|c|}
\hline Symbol & Description & Units \\
\hline$C_{k}$ & Concentration of dissolved species $k$ & $m g \cdot L^{-1}$ \\
\hline$D$ & Hydrodynamic dispersion tensor & $m^{2} \cdot d^{-1}$ \\
\hline$D_{W B}$ & Depth of the Wetland Body subdomain & $m$ \\
\hline$h$ & Hydraulic head & $m$ \\
\hline$K$ & Hydraulic conductivity & $m \cdot d^{-1}$ \\
\hline$k_{r}$ & Relative hydraulic conductivity & - \\
\hline$K_{\text {sat }}$ & Saturated hydraulic conductivity & $m \cdot d^{-1}$ \\
\hline$k_{X}$ & Decay rate of $X$ & $d^{-1}$ \\
\hline$K_{X, C}$ & Saturation/inhibition coefficient of $X$ by $C$ & $m g \cdot L^{-1}$ \\
\hline$L_{W B}$ & Length of the Wetland Body subdomain & $m$ \\
\hline$m$ & van Genuchten parameter $\left(m=1-\frac{1}{n}\right)$ & - \\
\hline$N_{i}$ & Number of pores of radius $r_{i}$ & - \\
\hline$n$ & van Genuchten parameter & - \\
\hline$P_{c}$ & Soil capillary pressure & $P a$ \\
\hline$r_{C_{k}}$ & Reaction rate of $C_{k}$ & $m g \cdot L^{-1} \cdot d^{-1}$ \\
\hline$r_{i}$ & Radius of capillaries filled with water at $P_{c_{i}}$ & $m$ \\
\hline$s_{C_{k}}$ & Sources or sinks of $C_{k}$ & $m g \cdot L^{-1} \cdot d^{-1}$ \\
\hline$S_{e}$ & Specific water saturation & - \\
\hline$t$ & Time & $d$ \\
\hline th & Biofilm thickness & $m$ \\
\hline$U$ & Mostafa and van Geel (2007)'s flow reduction factor & - \\
\hline$u$ & Specific discharge & $m \cdot d^{-1}$ \\
\hline$V_{m}$ & Biomass volume per cubic meter & $m^{3} \cdot m^{-3}$ \\
\hline$W_{W B}$ & Width of the Wetland Body subdomain & $m$ \\
\hline$X$ & Concentration of bacteria biomass & $m g \cdot L^{-1}$ \\
\hline$x_{C M}$ & $\mathrm{x}$ coordinate of the center of mass of bacteria & $m$ \\
\hline$y_{C M}$ & $y$ coordinate of the center of mass of bacteria & $m$ \\
\hline$Y_{X, C}$ & Yield coefficient for bacteria $X$ on substrate $C$ & $d^{-1}$ \\
\hline$\alpha$ & van Genuchten parameter & $m^{-1}$ \\
\hline$\alpha_{T}$ & Transverse dispersivity & $m^{2} \cdot s^{-1}$ \\
\hline$\alpha_{L}$ & Longitudinal dispersivity & $m^{2} \cdot s^{-1}$ \\
\hline$\beta$ & Water contact angle within the tube walls & - \\
\hline$\mu_{X}$ & Maximum specific growth rate of $X$ & $d^{-1}$ \\
\hline$\rho_{X}$ & Density of bacteria $X$ & $k g \cdot m^{-3}$ \\
\hline & Water surface tension & $N \cdot m^{-1}$ \\
\hline$\sigma(h)$ & Specific volumetric storability & $m^{-1}$ \\
\hline$\theta$ & Liquid volume fraction & $m^{3} \cdot m^{-3}$ \\
\hline$\theta_{r}$ & Residual liquid volume fraction & $m^{3} \cdot m^{-3}$ \\
\hline$\theta_{s}$ & Saturated liquid volume fraction & $m^{3} \cdot m^{-3}$ \\
\hline
\end{tabular}


Table 1: Mesh characteristics.

\begin{tabular}{|l|c|c|}
\cline { 2 - 3 } \multicolumn{1}{c|}{} & \begin{tabular}{c} 
Mixing zone and \\
\multicolumn{1}{c|}{} \\
Wetland body
\end{tabular} & Runoff layer \\
\hline Maximum element size & $0.0442 \mathrm{~m}$ & $0.012 \mathrm{~m}$ \\
\hline Minimum element size & $0.00198 \mathrm{~m}$ & $9.75 \cdot 10^{-5} \mathrm{~m}$ \\
\hline Maximum element growth rate & 1.2 & 1.08 \\
\hline Resolution of curvature & 0.4 & 0.25 \\
\hline Resolution in narrow regions & 1 & 4 \\
\hline Total Number of & \multicolumn{2}{c}{15358} \\
\hline triangular elements & \multicolumn{2}{c|}{} \\
\hline
\end{tabular}

${ }^{a}$ A predefined number of 350 triangular elements was set at boundary $B 4$ of the domain (see Figure 2) to avoid water mass losses from inlet to outlet.

Table 2: Values of the biokinetic parameters of Eqs. 3 and 4.

\begin{tabular}{|l|c|c|c|}
\hline Parameter & Value & Unit & Description \\
\hline$\mu_{X}$ & 2 & $d^{-1}$ & Maximum growth rate of $X$ \\
\hline$k_{X}$ & 0.05 & $d^{-1}$ & Decay rate of bacteria $X$ \\
\hline$K_{X, C}$ & 40 & $m g C O D \cdot L^{-1}$ & Half saturation coefficient of $X$ for $C$ \\
\hline$Y_{X, C}$ & 0.1 & $K g C O D_{X} \cdot K g C O D_{C}{ }^{-1}$ & Yield coefficient for bacteria $X$ \\
\hline$\rho_{X}$ & 1 & $K g \cdot m^{-3}$ & Density of bacteria $X$ \\
\hline
\end{tabular}


Table 3: Values of the hydrodynamic parameters of the wetland body $(W B)$, the mixing zone $(M Z)$ and the runoff layer $(R L)$.

\begin{tabular}{|c|c|c|c|c|}
\hline \multirow[b]{2}{*}{ Parameter } & \multicolumn{3}{|c|}{ Values } & \multirow[b]{2}{*}{ Unit } \\
\hline & WB & MZ & RL & \\
\hline$\alpha$ & \multicolumn{2}{|c|}{14.5} & 150 & $m^{-1}$ \\
\hline$n$ & \multicolumn{3}{|c|}{2.68} & - \\
\hline$m$ & $1-$ & & 1 & - \\
\hline$\theta_{s}$ & 0. & & 1 & - \\
\hline$\theta_{r}$ & 0. & & 0 & - \\
\hline$K_{\text {sat }_{L}}$ & 10 & & 1500 & $m \cdot d^{-1}$ \\
\hline$K_{s a t_{T}}$ & 10 & & 10000 & $m \cdot d^{-1}$ \\
\hline$\alpha_{L}$ & 0. & & 0 & $m$ \\
\hline$\alpha_{T}$ & 0.0 & & 0 & $m$ \\
\hline$D$ & $1 \cdot 1$ & $0^{-9}$ & $1 \cdot 10^{-9} \cdot \theta^{1}$ & $m^{2} \cdot d^{-1}$ \\
\hline
\end{tabular}


Table 4: Values of the total area of pores and biofilm thickness (for $V_{m}=0.3$ ) for discretisations of the saturation range of 10, 100, 1000, 10000 and 100000 disivisions. Note that the simulation results presented in this work were carried out using a discretization of 500 divisions.

\begin{tabular}{|l|c|l|}
\hline Number of divisions & Area of pores $\left(\mathrm{m}^{2}\right)$ & Biofilm thickness $\left(\mathrm{m}^{2}\right)$ \\
\hline 10 & 0.380000000000000 & $1.017374999999997 e-04$ \\
\hline 100 & 0.380000000000001 & $1.025749999999997 e-04$ \\
\hline 500 & 0.379999999999998 & $1.026062499999997 e-04$ \\
\hline 1000 & 0.379999999999995 & $1.026124999999997 e-04$ \\
\hline 10000 & 0.379999999999970 & $1.026124999999997 e-04$ \\
\hline 100000 & 0.379999999999911 & $1.026124999999997 e-04$ \\
\hline
\end{tabular}

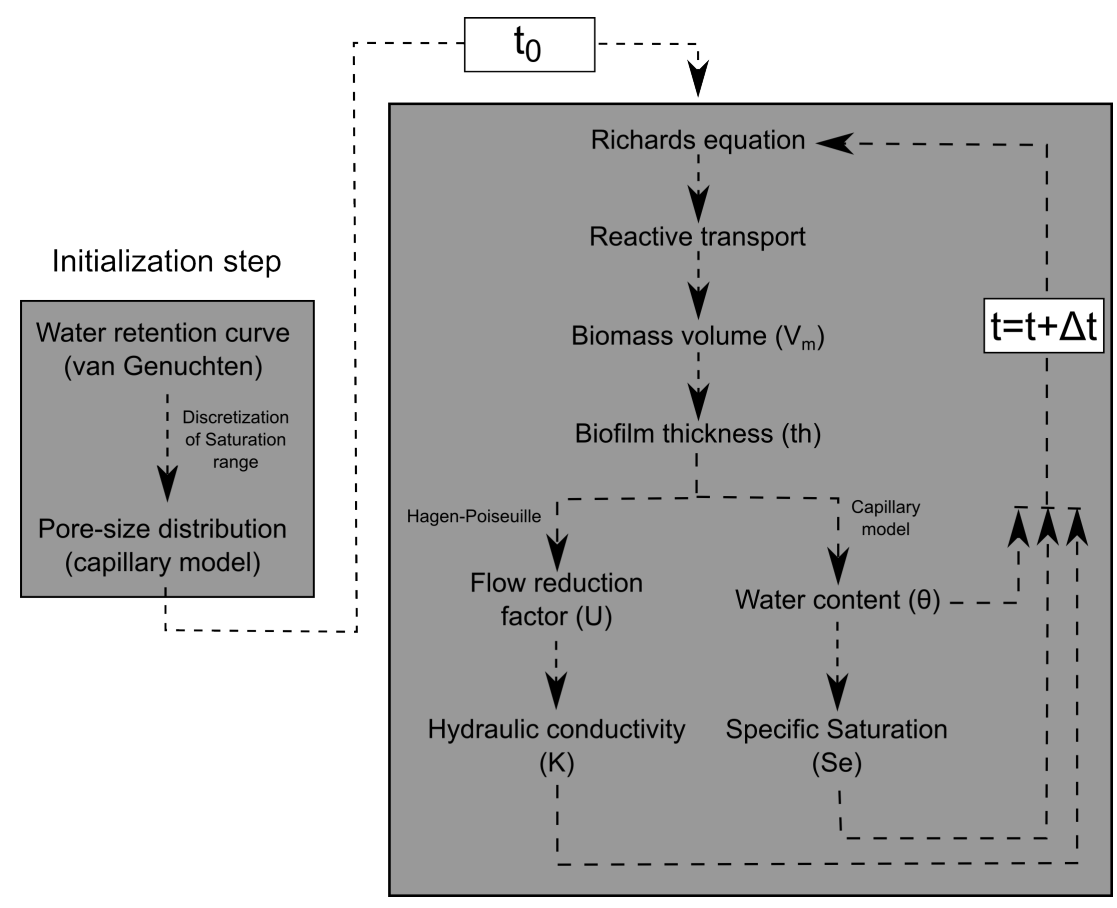

Figure 1: Graphical representation of the simulation steps. 


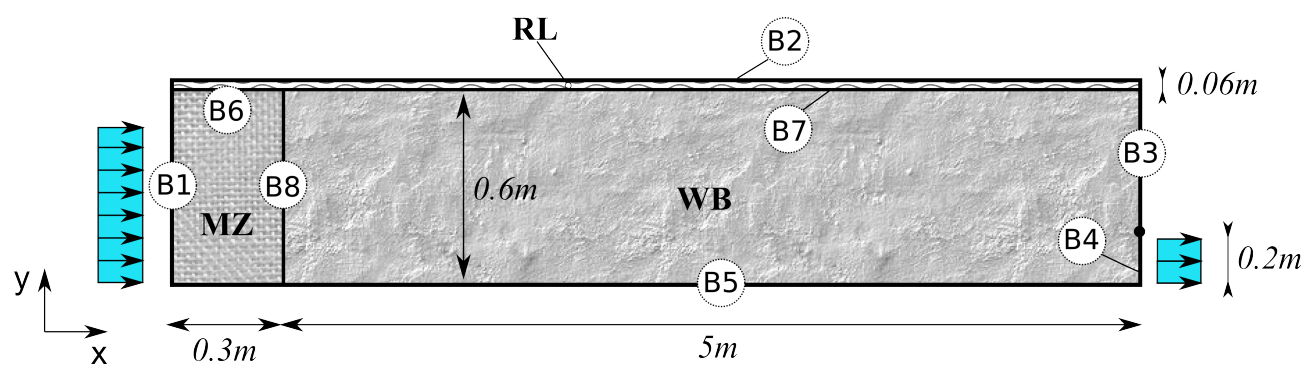

Figure 2: Schematic representation of the model domain, including the mixing zone (MZ), the body of the wetland (WB) and the runoff layer (RL). $B 1$ to $B 8$ are the names assigned to the different boundaries in the domain. Notice that the y-axes is exaggerated so that the image fits a reasonable size.

10 days
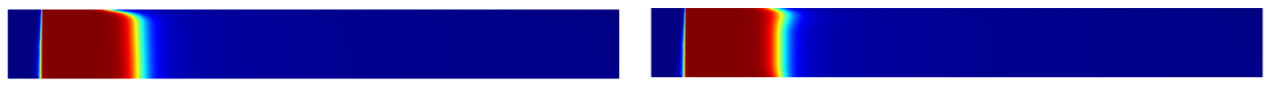

25 days
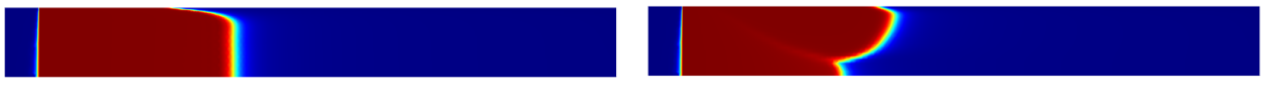

125 days
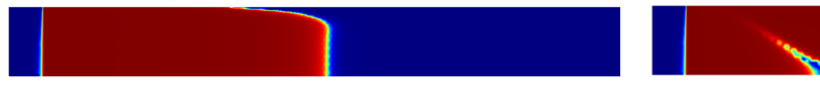

Figure 3: Concentration of bacteria $X$ (in $m g C O D \cdot L^{-1}$ ) within the domain with and without the effects of bioclogging after 10 (top), 25 and 125 (bottom) days. Note that the $R L$ subdomain is not represented in this figure, since bacteria is assumed to not grow in this region. 


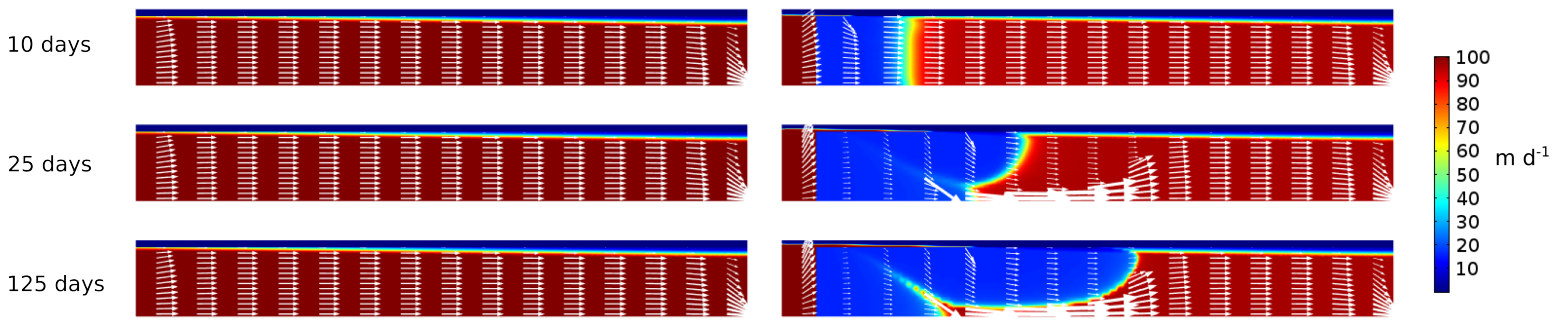

Figure 4: Hydraulic conductivity $(K)\left(m \cdot d^{-1}\right)$ within the domain with and without the effects of bioclogging after 10 (top), 25 and 125 (bottom) days. The white arrows indicate the direction of the velocity vector at every location within the domain.

Without bioclogging

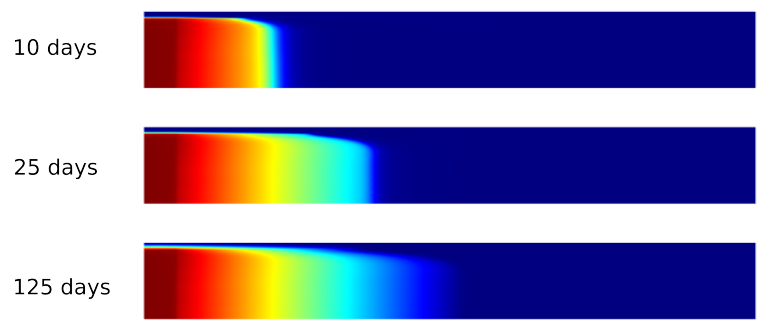

With bioclogging

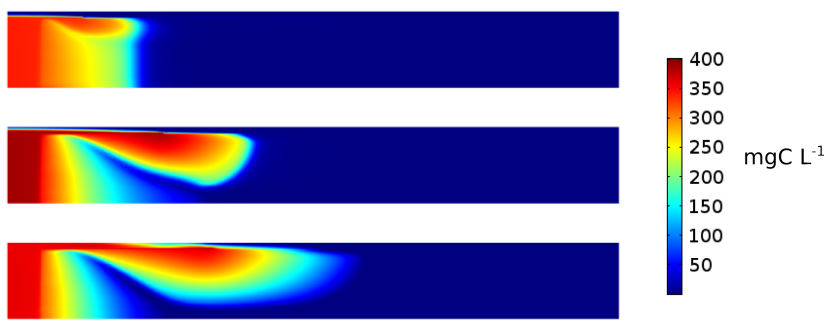

Figure 5: Substrate $C$ concentration $\left(m g C \cdot L^{-1}\right)$ within the domain with and without the effects of bioclogging after 10 (top), 25 and 125 (bottom) days. 


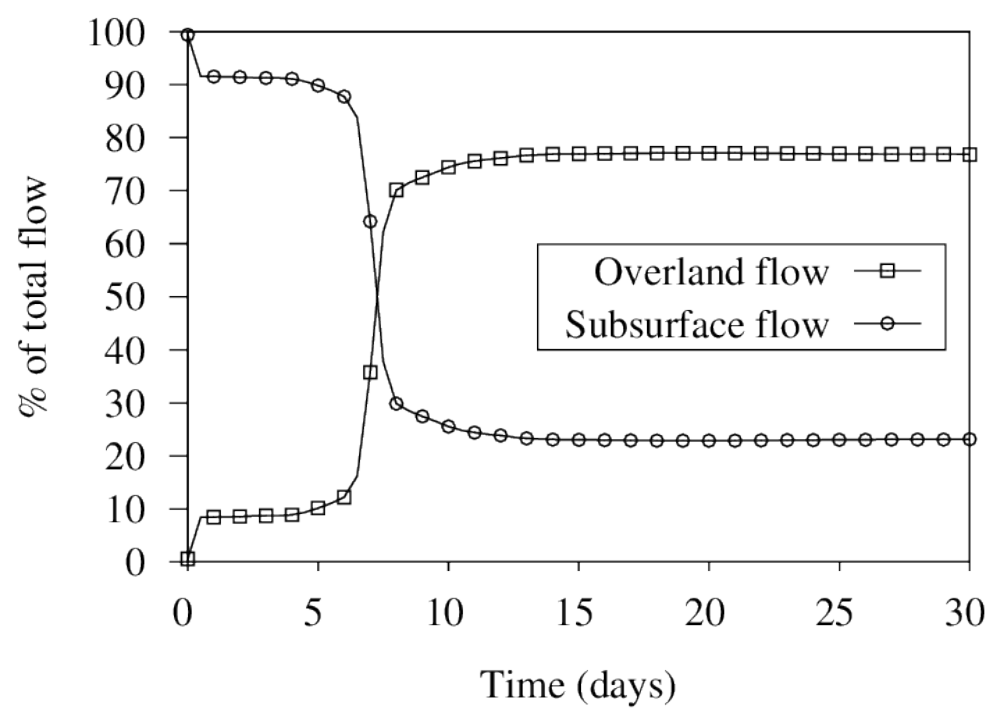

Figure 6: Proportion of overland (passing through boundary B6) and subsurface (passing through boundary B8) flow obtained with bioclogging (Eq. 16). Notice that without bioclogging, no surface flow develops. 
a)

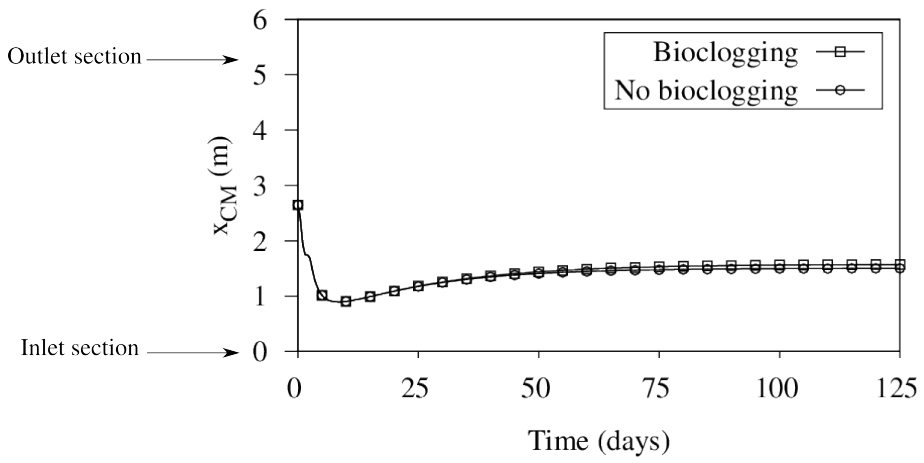

b)

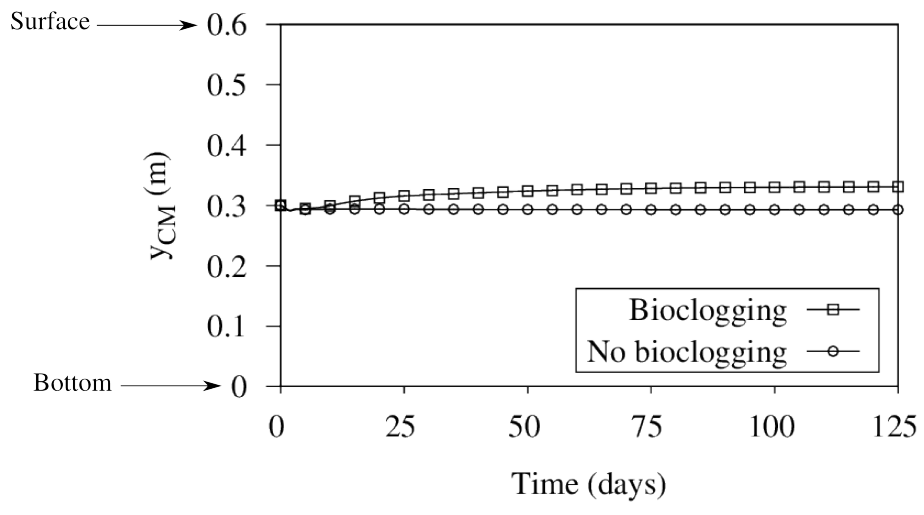

Figure 7: Evolution of coordinate $x(\mathrm{a})$ and $y(\mathrm{~b})$ of the center of mass of bacteria $X$ in the $W B$ with and without bioclogging (Eqs. 14 and 15). 


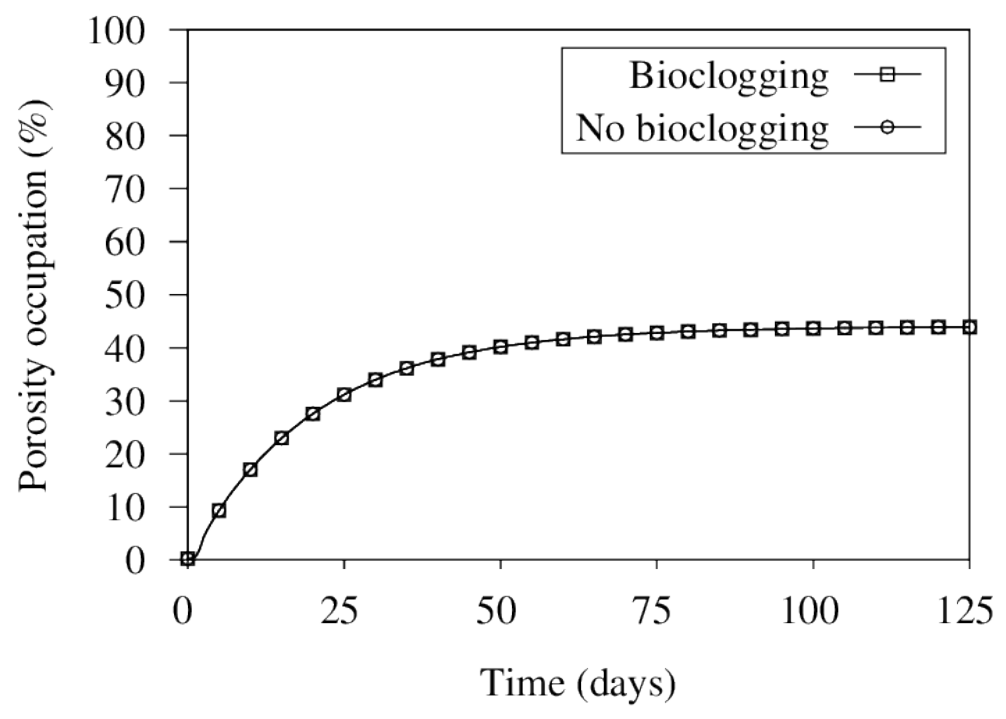

Figure 8: Proportion of the $W B$ occupied by bacteria over time with and without bioclogging (Eq. 16).

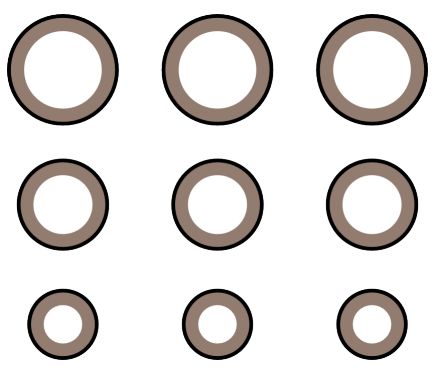

Figure 9: Uniform biofilm thicknes across all pore sizes (adapted from Mostafa and van Geel (2007)). 